Article

\title{
Fast and Selective Aqueous-Phase Oxidation of Styrene to Acetophenone Using a Mesoporous Janus-Type Palladium Catalyst
}

\author{
Majid Vafaeezadeh *(D), Ranja Saynisch, Andrea Lösch $(D$, Wolfgang Kleist $(D)$ and Werner R. Thiel *(D) \\ Fachbereich Chemie, Technische Universität Kaiserslautern, Erwin-Schrödinger-Str. 54, \\ D-67663 Kaiserslautern, Germany; saynisch@rhrk.uni-kl.de (R.S.); loesch@chemie.uni-kl.de (A.L.); \\ kleist@chemie.uni-kl.de (W.K.) \\ * Correspondence: majidvafaeezadeh@yahoo.com (M.V.); thiel@chemie.uni-kl.de (W.R.T.)
}

\section{check for} updates

Citation: Vafaeezadeh, M.; Saynisch, R.; Lösch, A.; Kleist, W.; Thiel, W.R. Fast and Selective Aqueous-Phase Oxidation of Styrene to

Acetophenone Using a Mesoporous Janus-Type Palladium Catalyst. Molecules 2021, 26, 6450. https:// doi.org/10.3390/molecules26216450

Academic Editors: Margarita D.

Popova and Hristiyan A.

Aleksandrov

Received: 16 September 2021

Accepted: 19 October 2021

Published: 26 October 2021

Publisher's Note: MDPI stays neutral with regard to jurisdictional claims in published maps and institutional affiliations.

Copyright: (c) 2021 by the authors. Licensee MDPI, Basel, Switzerland. This article is an open access article distributed under the terms and conditions of the Creative Commons Attribution (CC BY) license (https:// creativecommons.org/licenses/by/ $4.0 /)$.
Abstract: A heterogeneous Janus-type palladium interphase catalyst was obtained by selective surface modification of a hollow mesoporous silica material. The catalyst comprises hydrophobic octyl groups on one side of the silica nanosheets and single-site bis-imidazoline dichlorido palladium(II) complexes on the other. The structure of this composite material has been analyzed by means of elemental analysis, atomic absorption spectroscopy, BET surface analysis, TGA, SEM and solid-state CP-MAS ${ }^{13} \mathrm{C}$ and ${ }^{29} \mathrm{Si}$ NMR spectroscopy. The catalyst showed extraordinary activity for the aqueousphase oxidation of styrene to acetophenone using 30\% hydrogen peroxide as the oxidant. An $88 \%$ yield of acetophenone could be achieved after $60 \mathrm{~min}$.

Keywords: mesoporous Janus-type catalyst; modified mesoporous silica; aqueous-phase oxidation; palladium catalyst; hydrogen peroxide

\section{Introduction}

The Wacker oxidation is an industrial method for the conversion of ethylene to acetaldehyde. It has been performed by employing catalytic amounts of palladium together with stoichiometric amounts of copper salts as the co-catalyst [1]. The procedure is also well known for the oxidation of other terminal olefins [2], allowing for the preparation of valuable chemicals such as ketones, epoxides or benzaldehyde derivatives using either $\mathrm{O}_{2}$ [3-6], hydrogen peroxide $\left(\mathrm{H}_{2} \mathrm{O}_{2}\right)$ [7-10] or tert-butyl hydroperoxide (TBHP) [11,12] as the most common oxidants. Among the employed oxidants, $\mathrm{H}_{2} \mathrm{O}_{2}$ can be considered as a less hazardous oxidant since water is the sole by-product of the reaction and the use of copper as co-catalyst is not necessary. Moreover, due to the development of novel technologies during the last decades, the production of $\mathrm{H}_{2} \mathrm{O}_{2}$ is a cheap and safe process [13].

Several homogeneous and heterogeneous palladium catalysts were employed for this reaction in the past [3-12,14-17]. While homogeneous palladium catalysts showed rather high efficiencies, they suffer from the poor recovery of the expensive noble metal. Moreover, in some case, the reaction proceeded well only in the presence of expensive organic ligands or additives [18-21]. In contrast, heterogeneous catalysts allow a simple recovery and separation of the palladium source. However, they encounter a number of limitations for the Wacker oxidation: the reaction rate of the heterogeneous catalyst is lower, and hence, longer reaction times are required to achieve desirable conversions. Increasing the reaction time may deactivate the palladium centers on the surface of the applied support and in consequence, request more energy to complete the reaction. Another challenge of a long-time oxidation reaction is related to the gradual decomposition of $\mathrm{H}_{2} \mathrm{O}_{2}$. Therefore, in some cases, up to 10 equiv. of the oxidant had to be added [9], which is not a cost-effective and sustainable protocol for an oxidation reaction. 
A routine method for the synthesis of heterogeneous metal catalysts is the deposition of the metal nanoparticles on the surface of the support. Although this seems to be a fairly simple procedure, it suffers from noticeable leaching of the metal from the surface and undesirable steric effect between the surface and the reactants. In the case of palladium catalysts, this often leads to a rapid termination of the catalyst's activity via the formation of inactive palladium black species.

By employing heterogeneous interphase catalysts, it was possible to improve the catalytic activity to some extent [22]. In interphase catalysts, the active centers are connected with covalent bonds to the surface via an organic spacer and hence, are in principle far away from the surface's steric effects. This method also allows the immobilization of site-isolated metal complexes. However, compared to homogeneous catalysts, the efficiency of such catalysts is still far from a desirable threshold.

Janus-type materials are anisotropic double-face architectures, which have successfully been introduced as a new material generation for heterogeneous catalysis [23]. Due to their unique properties, Janus-type catalysts can bridge the gap between homo- and heterogeneous catalysts by combination of the activity of homogeneous systems and the simple separation and storage of the heterogeneous ones.

Recently, we established the concept of "Janus interphase catalysts" [24]. In this type of solid catalyst, the surface polarity can be manipulated by incorporation of in principle any type of organic group having a specific polarity with the aim of improving the mass transfer of the substrates to the active centers. Consequently, heterogeneous Janus-type interphase catalysts with overall higher activities compared to the classical heterogeneous catalysts have been generated [25-28].

To this aim, we introduced simple and practical techniques for the synthesis of heterogeneous Janus-type interphase catalysts by a modification of the Stöber process [29-31]. The catalysts showed high activity for the synthesis of a series of fine chemicals. The presence of water either as the solvent or as a by-product has no negative effects on the reaction efficiency. In order to extend this concept, we wish to disclose the first Janus-type interphase palladium catalyst and its applications for the Wacker-type oxidation of styrene to acetophenone employing $\mathrm{H}_{2} \mathrm{O}_{2}$ as the oxidant. Thanks to the unique structure of the material, it shows higher activity even in comparison to a homogeneous $\mathrm{PdCl}_{2}$-based system.

\section{Results and Discussion}

The material was prepared from commercially available starting materials (Scheme 1). In the first step, hollow spheres with octyl groups $(R)$ that are covalently immobilized on the inner surface were prepared by using a modified Stöber method for the preparation of monodisperse silica particles followed by removing of the surfactant to yield the mesoporous hollow structure 1. After crushing the hollow particles, the palladium precursor was grafted to the surface to form the final catalyst 2.

The loading of palladium in the catalyst was determined based on an atomic absorption spectroscopy (AAS) to be $0.22 \mathrm{mmol} \cdot \mathrm{g}^{-1}$.

Scanning electron microscope (SEM) images of material $\mathbf{1}$ and $\mathbf{2}$ are presented in Figure 1. Material 1 shows the expected geometry with rather monodisperse spheres of approximately $1 \mu \mathrm{m}$ in diameter (Figure 1a). After crushing, nanosheets of catalyst 2 were formed (Figure 1b). To find evidence for a selective surface functionalization of catalyst 2, the material in the middle of crushing process was labelled with negatively charged citrate-capped $\mathrm{Fe}_{3} \mathrm{O}_{4}$ nanoparticles $\left(\mathrm{Fe}_{3} \mathrm{O}_{4} @\right.$ citrate) according to our previously described procedure [30]. 


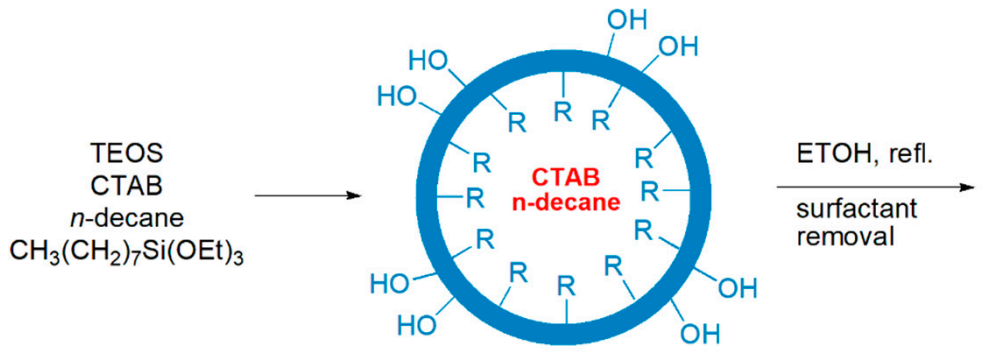

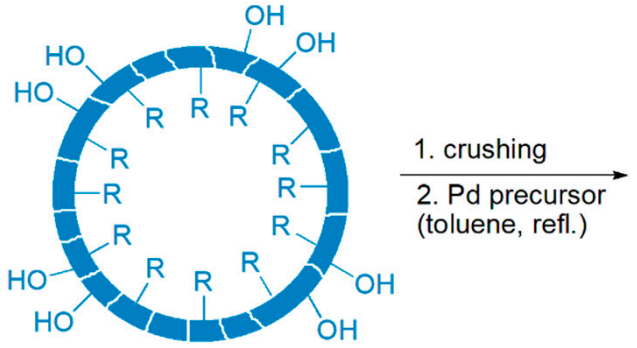

1
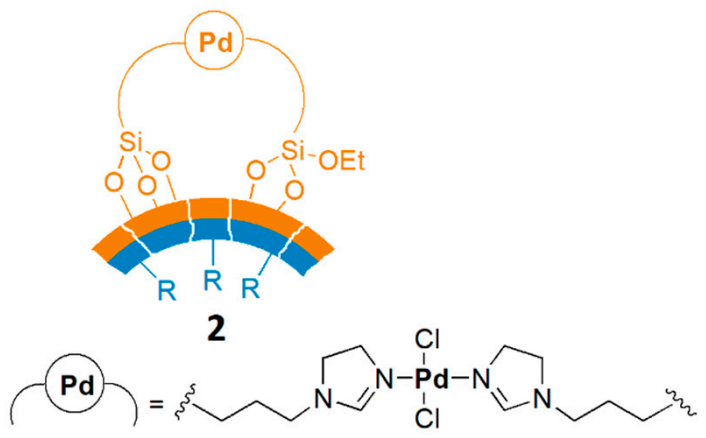

$\mathbf{R}=$ octyl

Scheme 1. Schematic synthesis of the heterogeneous Janus-type Pd interphase catalyst 2.
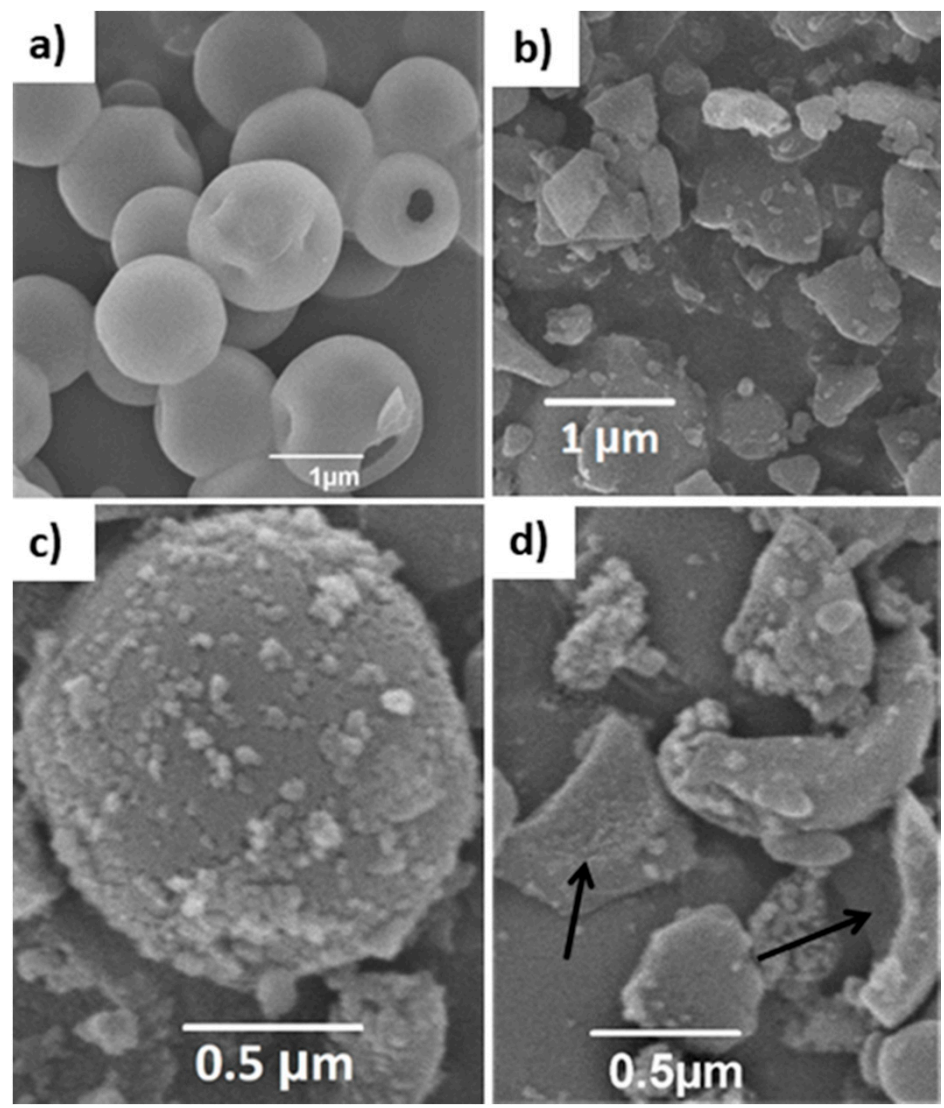

Figure 1. (a) SEM images of the hollow spheric material 1, (b) nanosheets of the final catalyst 2, (c) outer surface of catalyst 2 after the labelling experiment and (d) the inner surface of catalyst 2 after the labelling experiment. 
After labelling the catalyst by mixing it with citrate@ $\mathrm{Fe}_{3} \mathrm{O}_{4}$, the outer surface of the material that contains the nitrogen ligand can interact with the labelling agent (Figure 1c), while due to lack of noticeable functionality of the inner surface (i.e., relatively inert octyl groups), it remained almost remains untouched (Figure 1d).

The $\mathrm{N}_{2}$ adsorption/desorption isotherms of materials $\mathbf{1}$ and catalyst $\mathbf{2}$ (Figure 2,) show a type IV profile, which is typical for mesoporous materials. The calculated BET surface areas, the average pore diameters (BJH method) and the pore volumes for the hollow material 1 are $1045 \mathrm{~m}^{2} \cdot \mathrm{g}^{-1}, 2.29 \mathrm{~nm}$ and $0.60 \mathrm{~mL} \cdot \mathrm{g}^{-1}$, while the corresponding values for the final catalyst 2 are $848 \mathrm{~m}^{2} \cdot \mathrm{g}^{-1}, 2.45 \mathrm{~nm}$ and $0.52 \mathrm{~mL} \cdot \mathrm{g}^{-1}$, respectively. This observation suggests that after the functionalization of material 1, the specific surface area as well as pore volume in the final crushed catalyst 2 are reduced, which is reasonable evidence for the successful functionalization.

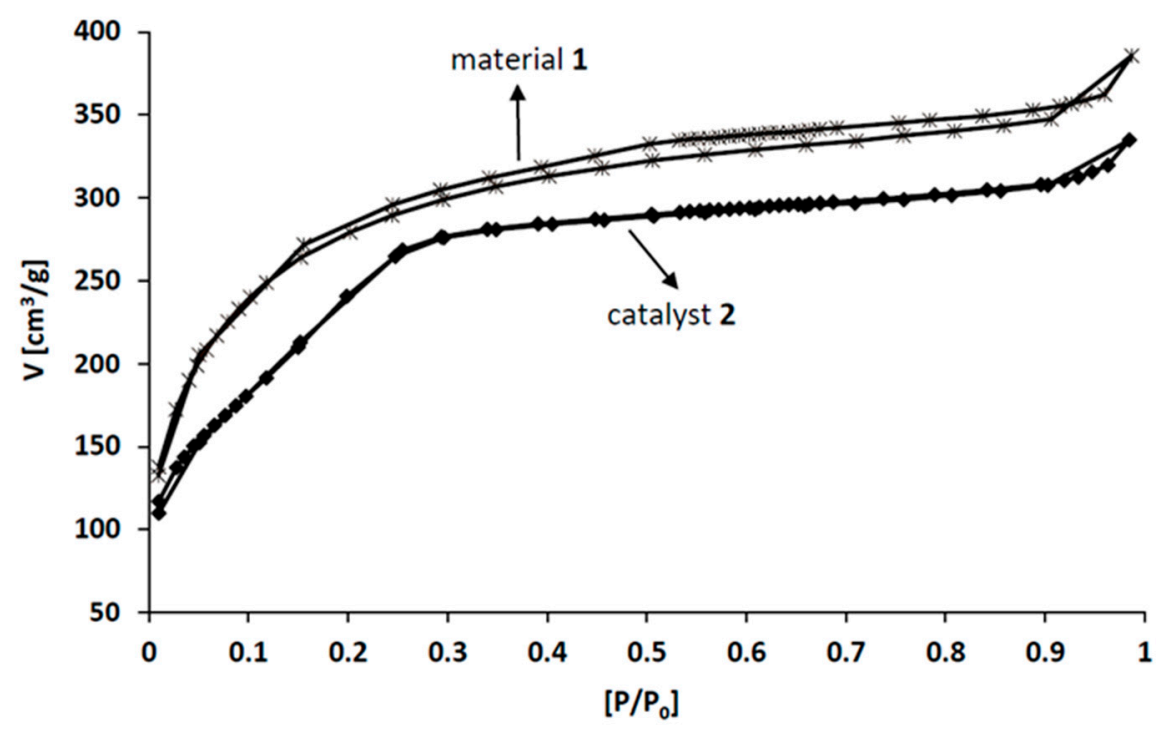

Figure 2. $\mathrm{N}_{2}$ adsorption/desorption isotherms of material 1 and catalyst 2.

Comparative thermogravimetric analysis (TGA) results for materials $\mathbf{1}$ and $\mathbf{2}$ are presented in Figure 3. It can be deduced from this thermogram that catalyst 2 is stable up to $300{ }^{\circ} \mathrm{C}$. A small weight loss $(\sim 5 \%)$ was found by heating the sample up to this temperature, which is attributed to the removal of physisorbed water. However, the presence of water in material 1 is approximately $15 \%$, which indicates the higher affinity of material 1 to water due to the presence of -OH groups on the outer surface. Consequently, catalyst 2 has a balanced hydrophobicity/hydrophilicity and is suitable for aqueous phase oxidation reactions of organic compounds [32].

The nature of the surface functionalities of catalyst 2 was investigated in more detail by means of solid-state CP-MAS ${ }^{13} \mathrm{C}$ NMR spectroscopy (Figure $4 \mathrm{a}$ ). Directly bound to the silicon atoms, the carbon atoms $\mathrm{C} 1$ and $\mathrm{C} 11$ are highly shielded and are assigned to the resonances at 8.3 and $11.8 \mathrm{ppm}$, respectively. The methyl groups (carbon atoms C8 and $\mathrm{C10}$ ) provide resonances at 16.1 and $16.5 \mathrm{ppm}$. Due to their similar chemical shifts, carbon atoms C2, C7 and C12 give rise to an intense resonance at $21.8 \mathrm{ppm}$. Two sharp and intense resonances at 28.7 and 31.5 ppm are assigned to carbon atoms C4 and C5 as well as C3 and C6, respectively. Although carbon atoms C13-15 have similar chemical shifts, they can fairly be distinguished in the region from 46.3 to $51.9 \mathrm{ppm}$. The resonance of some residual ethoxy groups coming from the grafted octyl groups as well as from the palladium complex precursors is observed at $58.5 \mathrm{ppm}$ and the resonance of the unique $\mathrm{sp}^{2}$-hybridized carbon atom C16 is observed at $159.9 \mathrm{ppm}$. 


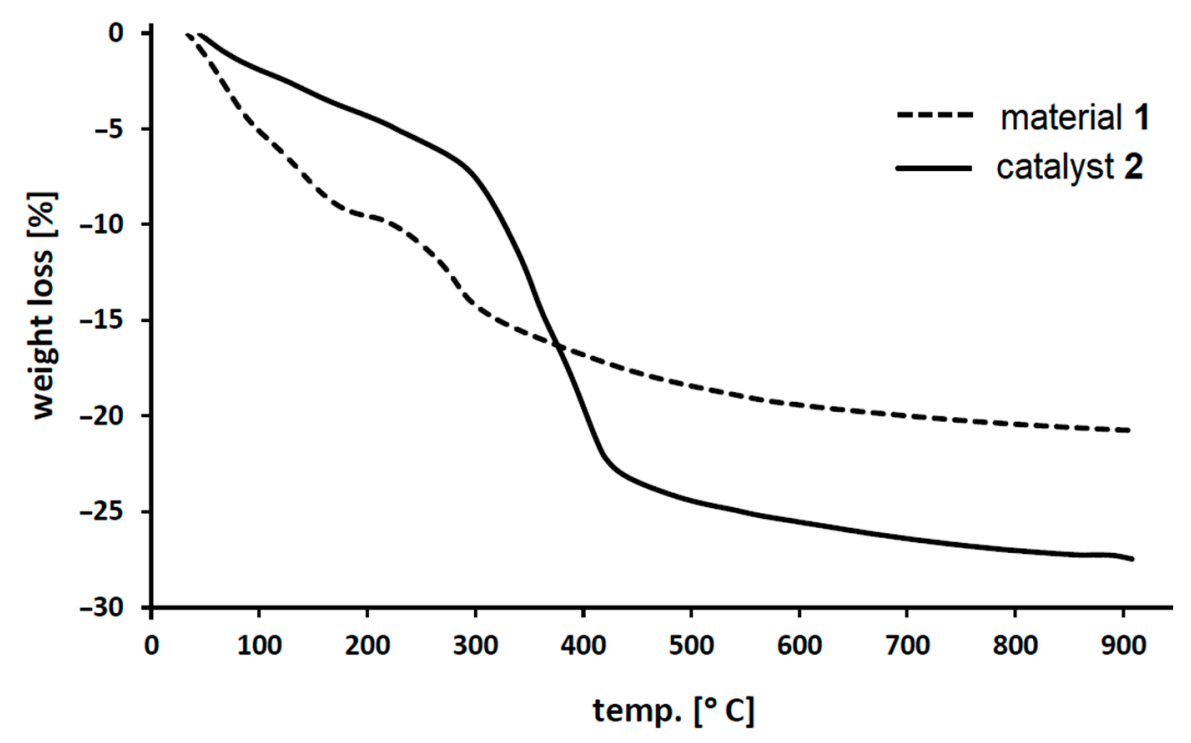

Figure 3. TGA of material 1 and catalyst 2.

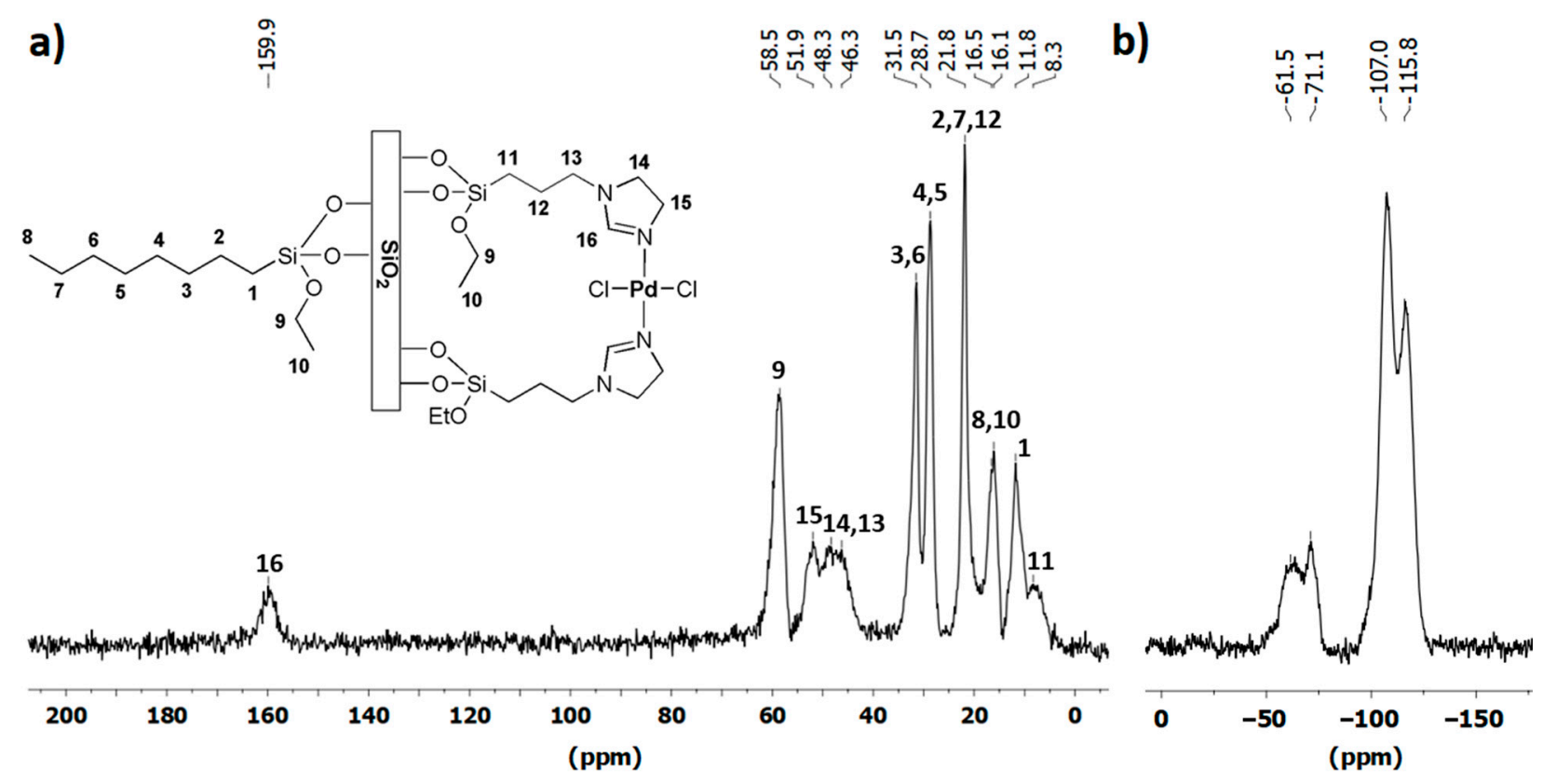

Figure 4. (a) Solid-state ${ }^{13} \mathrm{C}$ and (b) ${ }^{29} \mathrm{Si} \mathrm{CP}-\mathrm{MAS}$ NMR spectra of catalyst 2.

The ${ }^{29} \mathrm{Si}$ CP-MAS NMR spectrum of catalyst 2 (Figure $4 \mathrm{~b}$, right side) exhibits two dominant resonances at -107 and $-116 \mathrm{ppm}$, being attributed to $\mathrm{Q}^{3}\left[\mathrm{Si}(\mathrm{OSi})_{3} \mathrm{OH}\right]$ resp. $\mathrm{Q}^{4}$ $\left[\mathrm{Si}(\mathrm{OSi})_{4}\right]$ species in the framework of the materials. The presence of $\mathrm{Q}^{3}$ signal in the solidstate ${ }^{29} \mathrm{Si}$ NMR is evidence for the presence of free hydroxyl $(-\mathrm{OH})$ groups, and hence, a partial hydrophilicity of catalyst 2 even after the second functionalization. Two further broad resonances in this spectrum at around -62 and $-71 \mathrm{ppm}$ can be assigned to $\mathrm{T}^{2}$ $\left[\mathrm{RSi}(\mathrm{OSi})_{2}(\mathrm{OH})\right]$ and $\mathrm{T}^{3}\left[\mathrm{RSi}(\mathrm{OSi})_{3}\right]$ units and thus provide further evidence for the successful covalent immobilization of the palladium precursors on the surface of the materials.

The activity of catalyst 2 was tested for the oxidation of styrene leading to acetophenone by employing $30 \%$ aq. $\mathrm{H}_{2} \mathrm{O}_{2}$. Unlike for other alkenes, controlling the selectivity for the oxidation of styrene is more difficult since beside the formation of acetophenone, benzaldehyde and styrene oxide are frequently found. By screening the effect of solvents, the best activity was observed in a mixture of acetic acid and water (1.4:0.6 mL). The results 
of the styrene oxidation using Janus-type catalyst 2 as well as a comparison with other catalytic systems are summarized in Table 1.

Table 1. A brief comparison of the activities of catalyst 2 in the oxidation of styrene to acetophenone and a comparison with some homogeneous and heterogeneous Pd catalysts used for this transformation (Ap: acetophenone; Ba: benzaldehyde).

\begin{tabular}{|c|c|c|c|c|c|c|c|c|}
\hline Entry & Catalyst (amount) & $\begin{array}{l}\text { Oxidant } \\
\text { (equiv.) }\end{array}$ & Time (h) & Solvent & $\begin{array}{l}\text { Temp. } \\
\left({ }^{\circ} \mathrm{C}\right)\end{array}$ & $\begin{array}{l}\text { Ap } \\
(\%)\end{array}$ & $\begin{array}{l}\mathrm{Ba} \\
(\%)\end{array}$ & Ref. \\
\hline 1 & - & $30 \% \mathrm{H}_{2} \mathrm{O}_{2}(3)$ & 1 & $\mathrm{AcOH} / \mathrm{H}_{2} \mathrm{O}^{\mathrm{a}}$ & 80 & - & $12^{b}$ & this work \\
\hline 2 & $\mathrm{PdCl}_{2}(1 \mathrm{~mol} \%)$ & $30 \% \mathrm{H}_{2} \mathrm{O}_{2}$ & 1 & $\mathrm{AcOH} / \mathrm{H}_{2} \mathrm{O}$ & 80 & $67^{\mathrm{b}}$ & $8^{\mathrm{b}}$ & this work \\
\hline 3 & $2(1 \mathrm{~mol} \%)$ & $30 \% \mathrm{H}_{2} \mathrm{O}_{2}(3)$ & 0.5 & $\mathrm{AcOH} / \mathrm{H}_{2} \mathrm{O}$ & 80 & $76^{\mathrm{b}}$ & $9^{b}$ & this work \\
\hline 4 & $2(1 \mathrm{~mol} \%)$ & $30 \% \mathrm{H}_{2} \mathrm{O}_{2}(3)$ & 1 & $\mathrm{AcOH} / \mathrm{H}_{2} \mathrm{O}$ & 80 & $88^{\mathrm{b}}$ & $9^{b}$ & this work \\
\hline 5 & $2(1 \mathrm{~mol} \%)$ & $30 \% \mathrm{H}_{2} \mathrm{O}_{2}(3)$ & 1 & $\mathrm{AcOH}$ & 80 & $82^{b}$ & $15^{b}$ & this work \\
\hline 6 & $2(1 \mathrm{~mol} \%)+\mathrm{CuCl}(10 \mathrm{~mol} \%)$ & $\mathrm{O}_{2}$ (balloon) & 16 & $\mathrm{AcOH} / \mathrm{H}_{2} \mathrm{O}$ & 80 & $63^{b}$ & $30^{\mathrm{b}}$ & this work \\
\hline 7 & $2(1 \mathrm{~mol} \%)$ & $\mathrm{TBHP}^{\mathrm{c}}(2)$ & 16 & $\mathrm{CH}_{3} \mathrm{CN}$ & 80 & - & $37^{b, d}$ & this work \\
\hline 8 & $2(1 \mathrm{~mol} \%)$ & $35 \% \operatorname{UHP}(3)$ & 16 & $\mathrm{AcOH} / \mathrm{H}_{2} \mathrm{O}$ & 80 & $47^{\mathrm{b}}$ & $19^{\mathrm{b}}$ & this work \\
\hline 9 & $\mathrm{Na}_{2} \mathrm{PdCl}_{4}(10 \mathrm{~mol} \%)$ & $\begin{array}{l}30 \% \mathrm{H}_{2} \mathrm{O}_{2} \\
\text { (n.d.) }\end{array}$ & 2.5 & aq. NMP & r.t. & 55 & n.d. & [33] \\
\hline 10 & $\mathrm{Pd}^{0} / \mathrm{C}(5 \mathrm{~mol} \%)$ & $30 \% \mathrm{H}_{2} \mathrm{O}_{2}(6)$ & 8 & $\mathrm{CH}_{3} \mathrm{CN}$ & 65 & $90^{\mathrm{e}}$ & n.d. & [16] \\
\hline 11 & $\mathrm{Pd} / \mathrm{Al}_{2} \mathrm{O}_{3}(2.5 w \mathrm{t} \%)$ & $30 \% \mathrm{H}_{2} \mathrm{O}_{2}(4)$ & 3 & $\mathrm{scCO}_{2}$ & 120 & $83^{\mathrm{f}}$ & 6 & [15] \\
\hline 12 & $\begin{array}{c}(\mathrm{PBO}) \mathrm{Pd}\left(\mathrm{CH}_{3} \mathrm{CN}\right)_{2}(\mathrm{OTf})_{2} \\
(1 \mathrm{~mol} \%)\end{array}$ & $50 \% \mathrm{H}_{2} \mathrm{O}_{2}(5)$ & 24 & $\mathrm{CH}_{3} \mathrm{CN}$ & r.t. & $80^{g}$ & n.d. & {$[18]$} \\
\hline 13 & $\mathrm{Pd}^{0} / \mathrm{RGO}(0.01 \mathrm{~g}), \mathrm{GO}(0.01 \mathrm{~g})$ & $30 \% \mathrm{H}_{2} \mathrm{O}_{2}(10)$ & 12 & $\mathrm{CH}_{3} \mathrm{CN} / \mathrm{H}_{2} \mathrm{O}$ & 55 & 93 & n.d. & [9] \\
\hline
\end{tabular}

${ }^{a}$ The amounts of $\mathrm{AcOH}: \mathrm{H}_{2} \mathrm{O}$ in all reactions were $1.4: 0.6 \mathrm{~mL}$. ${ }^{\mathrm{b}}$ Isolated yield. ${ }^{\mathrm{c}} 70 \%$ solution of $\mathrm{TBHP}$ in $\mathrm{H}_{2} \mathrm{O}$ was used. ${ }^{\mathrm{d}} 47 \%$ of styrene oxide was found. ${ }^{\text {e }} 0.2$ eq. $\mathrm{H}_{2} \mathrm{SO}_{4}$ was used as an additive. ${ }^{\mathrm{f}} 53 \%$ conversion of styrene. ${ }^{\mathrm{g}} 92 \%$ conversion of styrene. Abbreviations: n.d.: not determined; $\mathrm{AcOH}$ : acetic acid; UHP: urea hydrogen peroxide; $\mathrm{NMP}$ : N-methyl-2-pyrrolidone; $\mathrm{scCO}_{2}$ : supercritical $\mathrm{CO}_{2}$; PBO: 2-(2-pyridyl)benzoxazole; OTf: triflate; RGO: reduced graphene oxide.

To clarify a possible formation of peroxyacetic acid from the reaction of $\mathrm{AcOH}$ and $\mathrm{H}_{2} \mathrm{O}_{2}$ and its effect on the reaction, first, we studied a blank experiment in the absence of any palladium catalyst. No yield of acetophenone was observed after $1 \mathrm{~h}$ at $80^{\circ} \mathrm{C}$ by employing 3 equiv. of $30 \%$ aq. $\mathrm{H}_{2} \mathrm{O}_{2}$ (Table 1, entry 1). These conditions led to the formation of a small amount of benzaldehyde. By addition of $1 \mathrm{~mol} \%$ of palladium dichloride as the simplest example of a Pd-based catalyst, the yield of the acetophenone reached $67 \%$ accompanied by $8 \%$ of benzaldehyde as the major by-product (Table 1, entry 2 ). Surprisingly, $76 \%$ of acetophenone was found after $30 \mathrm{~min}$ when $45 \mathrm{mg}$ of 2 ( $1 \mathrm{~mol} \%$ equiv. of Pd) was used as the catalyst (Table 1, entry 3). This indicates that the activity of catalyst 2 is even higher than the activity of the $\mathrm{PdCl}_{2}$-based system providing rather identical selectivity. When the reaction time was increased to $1 \mathrm{~h}, 88 \%$ of acetophenone were isolated (Table 1, entry 4 ). The reaction in pure acetic acid $(2 \mathrm{~mL})$ also afforded good yields of acetophenone. However, it was lower than in the acetic acid $/ \mathrm{H}_{2} \mathrm{O}$ system and worse in selectivity (Table 1, entry 5). The possibility of a Wacker oxidation using $\mathrm{O}_{2}$ as oxidant was also investigated (Table 1, entry 6). It was found that the reaction can proceed well in the presence of $\mathrm{CuCl}$ as a co-catalyst but without a desirable selectivity for acetophenone.

tert-Butyl hydroperoxide (TBHP) is also known as an oxidant being suitable for the oxidation of styrene to styrene oxide [11,12]. However, no acetophenone at all was found when TBHP (70\% aq.) was used as the oxidant in the presence of catalyst 2. Instead, $47 \%$ of styrene oxide accompanied by $37 \%$ of benzaldehyde were formed (Table 1 , entry 7 ). Poor yield and selectivity were observed in the case when the urea adduct of hydrogen peroxide (35\% UHP) was applied as the oxidant (Table 1, entry 8 ).

The activity and selectivity of the heterogeneous Janus-type palladium catalyst for the oxidation of styrene was also compared with some reports of homogeneous and heterogeneous systems (Table 1, entries 9-13). As shown in Table 1, some of the reported protocols suffer from high amounts of palladium catalyst with the need for up to $10 \mathrm{~mol} \%$ of $\mathrm{Na}_{2} \mathrm{PdCl}_{4}$ or $5 \mathrm{~mol} \%$ of $\mathrm{Pd}^{0} / \mathrm{C}$ (Table 1, entries 9-10). Another drawback is employing a harsh reaction condition such as $\mathrm{scCO}_{2}$ at $120^{\circ} \mathrm{C}$, which resulted a poor conversion (Table 1, entry 11).The use of expensive ligands in concentrated $\mathrm{H}_{2} \mathrm{O}_{2}$ as the oxidant (Table 1, entry 12), or the need 
for applying up to 10 equiv. of the oxidant (Table 1, entry 13), are among the negative issues of the reported protocols. Consequently, the efficiency of the Janus-type catalyst 2 stands among the top of the reported homogeneous and heterogeneous systems in an economic and environmental point of view.

To study the reusability of catalyst 2, an experiment was set up with $135 \mathrm{mg}$ of the catalyst and $3.0 \mathrm{mmol}$ of styrene. At the end of the first run, it was cooled down to r.t. and the catalyst was separated by centrifugation and decanting of the reaction mixture. It was dried under vacuum and then reused for two subsequent reaction runs. The yields of the acetophenone for the 2 nd and the 3 rd reaction run were found to be $81 \%$ and $78 \%$, respectively, while $122 \mathrm{mg}$ of the catalyst were isolated at the end of the 3rd reaction run. The slight decrease of the yield can be explained by the small loss of catalyst during the recovery process, which means that there is no principal degradation of the catalyst. The elemental analysis of the recovered catalyst revealed the presence of $1.40 \%$ of nitrogen (from the ligand) in the catalyst. This value for the fresh catalyst was $1.42 \%$, which indicates very good stability of the Pd complex on the surface.

A proposed reaction mechanism is shown in Figure 5. Our attempt to convert styrene oxide to acetophenone in the presence of an identical amount of catalyst and without employment of any oxidant was not successful. This finding indicates that the reaction cannot proceed via the rearrangement of styrene oxide that is intermediately formed by epoxidation of styrene. In the first step, the reaction of the catalyst and hydrogen peroxide could form the hydroperoxidopalladium intermediate 3 on the surface of the material. The hydrophobic face (decorated with octyl groups) will efficiently accelerate the diffusion of the starting material to the active site. Consequently, styrene and the catalytically active species will meet each other on a nanometric temporary interface and react to produce the $\mathrm{Pd} \pi$-complex 4 that subsequently converts into the palladadioxa cyclopentane intermediate 5 . This undergoes a 1,2- $\mathrm{H}$ shift in combination with a cleavage of the $\mathrm{Pd}-\mathrm{C}$ and the $\mathrm{O}-\mathrm{O}$ bond to finally release acetophenone and the hydroxidopalladium species 6 . The reaction cycle then can be continued by the exchange of $\mathrm{HO}^{-}$against $\mathrm{HOO}^{-}$.

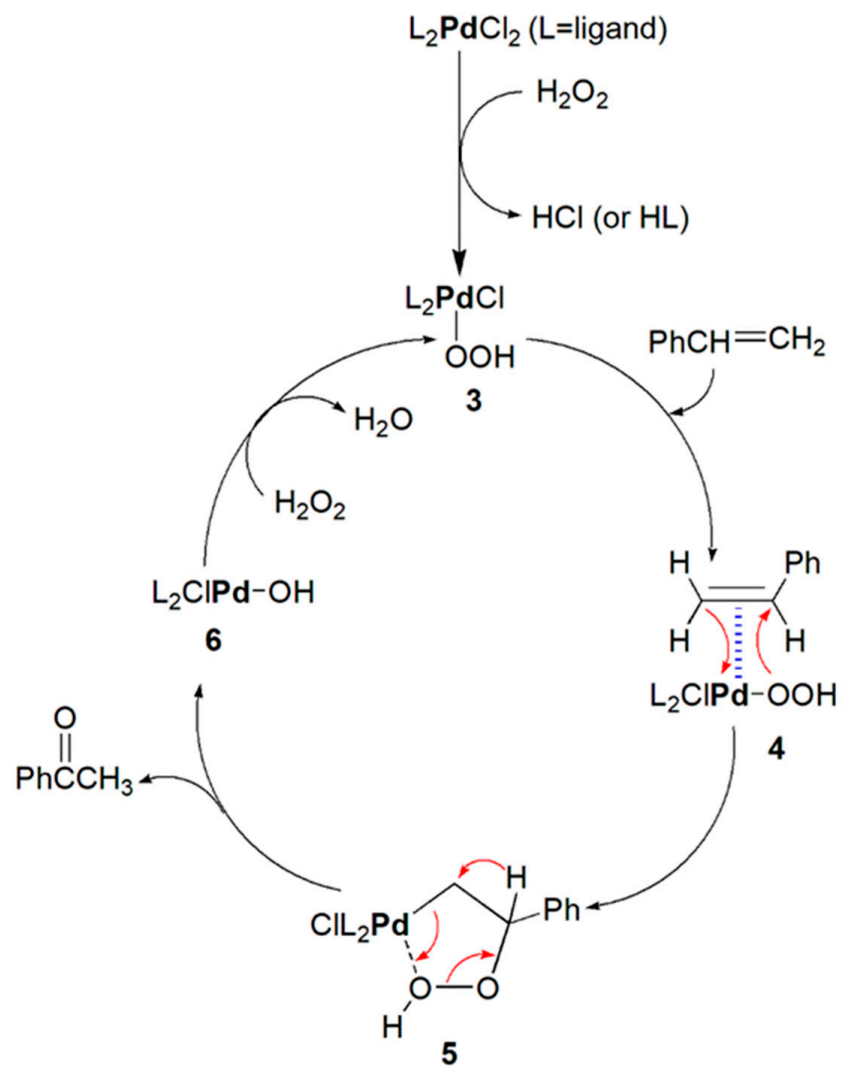

Figure 5. Postulated mechanism for the oxidation styrene to acetophenone. 


\section{Conclusions}

In summary, a novel mesoporous Janus-type palladium interphase catalyst was prepared and employed for the Wacker-type oxidation of styrene to acetophenone using 30\% $\mathrm{H}_{2} \mathrm{O}_{2}$ as the oxidizing agent. The material was prepared in a simple procedure using cheap starting materials. The catalyst shows excellent activity and selectivity for the synthesis of acetophenone by the oxidation of styrene. The activity and selectivity of the heterogeneous catalyst was found to be superior to a homogeneous $\mathrm{PdCl}_{2}$-based system. We assign the main reason for the high activity of this catalyst system to the balanced hydrophobicity/hydrophilicity because of the presence of surface silanol as well as octyl groups on its surface. This combination of functional groups can facilitate the oxidation in a narrow interface where aqueous oxidant and organic substrate meet each other.

\section{Materials and Methods}

\subsection{General Methods}

All chemicals and solvents were purchased from the suppliers and used without further purifications except pentane and toluene, which were dried before use. Solid state ${ }^{13} \mathrm{C}$ and ${ }^{29} \mathrm{Si}$ CP-MAS NMR spectra were measured using a $500 \mathrm{MHz}$ BRUKER Avance III spectrometer under cross polarization conditions with a spinning frequency of $11,000 \mathrm{~Hz}$ for both ${ }^{13} \mathrm{C}$ and ${ }^{29} \mathrm{Si}$ and with scan numbers of 15,000 and 2500 , respectively. TGA measurements were performed in synthetic air $\left(20.5 \% \mathrm{O}_{2}\right.$ in $\left.\mathrm{N}_{2}\right)$ on a SETARAM-Setsys-16 from $30{ }^{\circ} \mathrm{C}$ to $900{ }^{\circ} \mathrm{C}$ with a heating ramp of $10 \mathrm{~K} \mathrm{~min}^{-1}$. For $\mathrm{N}_{2}$ adsorption/desorption, the samples were activated for $24 \mathrm{~h}$ at $150{ }^{\circ} \mathrm{C}$ prior to the measurements. Adsorption and desorption isotherms were recorded using an Autosorb-1 setup from Quantachrome. The specific surface areas were determined using the BET method. Electron microscopy measurements were conducted on a Jeol JSM-6490LA operated at $15 \mathrm{kV}$. Prior to the measurements, the samples were sputter-coated with gold (JFC-1200 Fine Coater, Jeol, Tokyo, Japan) for $30 \mathrm{~s}$. High resolution ${ }^{1} \mathrm{H}$ and ${ }^{13} \mathrm{C}$ NMR analyses were performed with 400 and $600 \mathrm{MHz}$ BRUKER DPX spectrometers. An air-cooled condenser (Findenser ${ }^{\mathrm{TM}}$, SUPER air condenser, Radleys, Saffron Walden, Essex, UK) was used in the reactions instead of a water-cooled condenser.

\subsection{Synthesis of Material 1}

Material 1 was prepared according to our previously described procedure [29] followed by the crushing of the resulted hollow particles using mortar and pestle for $30 \mathrm{~min}$. Yield: $1.15 \mathrm{~g}$. Elemental analysis: C: $6.72 \%$ and H: $2.15 \%$.

\subsection{Synthesis of the Palladium Precursor}

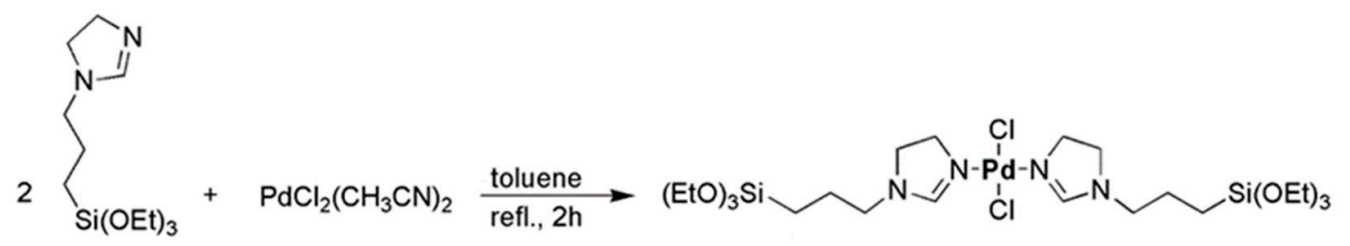

A solution of $0.28 \mathrm{~mL}(0.28 \mathrm{~g}, 1.02 \mathrm{mmol})$ of triethoxy-3-(2-imidazolin-1-yl)propylsilane and $0.130 \mathrm{mg}(0.5 \mathrm{mmol})$ of $\mathrm{PdCl}_{2}\left(\mathrm{CH}_{3} \mathrm{CN}\right)_{2}$ in $20 \mathrm{~mL}$ of toluene was heated for $2 \mathrm{~h}$ to reflux. At the end of the reaction, the flask was cooled to room temperature and the toluene was evaporated under vacuum. Residual amounts of unreacted silane precursor was washed out with dry pentane $(2 \times 15 \mathrm{~mL})$. The obtained material was dried under vacuum to afford $327 \mathrm{mg}(90 \%)$ of the product. ${ }^{1} \mathrm{H}$ NMR $\left(600 \mathrm{MHz}, \mathrm{CDCl}_{3}\right): 7.18(\mathrm{~s}, 2 \mathrm{H}), 3.72-3.82(\mathrm{~m}, 16 \mathrm{H})$, $3.25(\mathrm{t}, 4 \mathrm{H}), 3.08(\mathrm{t}, 4 \mathrm{H}), 1.54$ (quint. $4 \mathrm{H}), 1.16(\mathrm{t}, 18 \mathrm{H})$ and $0.47 \mathrm{ppm}(\mathrm{t}, 4 \mathrm{H}) .{ }^{13} \mathrm{C} \mathrm{NMR} \mathrm{in}^{\mathrm{CDCl}} \mathrm{ND}_{3}$ (151 MHz, $\mathrm{CDCl}_{3}$ ) in ppm: 159.9, 58.5, 53.0, 50.0, 46.9, 21.6, 18.3 and 7.3 ppm. Elemental analysis found: $\mathrm{C} 40.13, \mathrm{H} 6.92, \mathrm{~N} 7.98$, calcd. for $\mathrm{C}_{24} \mathrm{H}_{52} \mathrm{Cl}_{2} \mathrm{~N}_{4} \mathrm{O}_{6} \mathrm{PdSi}_{2}$ : C 39.69, H 7.22, N 7.72. 


\subsection{Synthesis of Catalyst 2}

In a $50 \mathrm{~mL}$ flask equipped with an air condenser, $254 \mathrm{mg}(0.35 \mathrm{mmol})$ of the palladium precursor were dissolved in $20 \mathrm{~mL}$ of dry toluene under an atmosphere of $\mathrm{N}_{2}$. Then, $1.00 \mathrm{~g}$ of the crushed material 1 was added to the flask and the mixture was heated to reflux for $24 \mathrm{~h}$. After cooling to room temperature, the solid was separated by centrifugation, washed several times with acetone and ethanol to remove traces of unreacted palladium precursor, and subsequently dried under vacuum. Yield: $1.18 \mathrm{~g}$. Elemental analysis: C 13.36\%, H $2.55 \%$, N $1.42 \%$.

\subsection{Typical Procedure for Palladium-Catalyzed Oxidation of Styrene Using 30\% $\mathrm{H}_{2} \mathrm{O}_{2}$}

Measures of $0.11 \mathrm{~mL}\left(104 \mathrm{mg}, 1 \mathrm{mmol}\right.$ ) of styrene, $1.4 \mathrm{~mL}$ of acetic acid, $0.6 \mathrm{~mL}$ of $\mathrm{H}_{2} \mathrm{O}$ and $0.31 \mathrm{~mL}$ ( $3.0 \mathrm{mmol})$ of $30 \% \mathrm{H}_{2} \mathrm{O}_{2}$ and $45 \mathrm{mg}(1.0 \mathrm{~mol} \%)$ of catalyst 2 were added to a round bottom flask. The mixture was heated to $80^{\circ} \mathrm{C}$ for $60 \mathrm{~min}$. At the end, the flask was cooled to room temperature and the catalyst was removed by filtration or centrifuging. The products were purified employing flash a chromatography apparatus with $n$-hexane/ethyl acetate as the solvents. The ratio of ethyl acetate was increased gradually from 0 to $10 \%$. Acetophenone: ${ }^{1} \mathrm{H}$ NMR $\left(400 \mathrm{MHz}, \mathrm{CDCl}_{3}\right): 7.89(\mathrm{~d}, 2 \mathrm{H}), 7.49(\mathrm{t}, 1 \mathrm{H}), 7.39(\mathrm{t}, 2 \mathrm{H})$ and $2.54 \mathrm{ppm}(\mathrm{s}, 3 \mathrm{H}) .{ }^{13} \mathrm{C} \mathrm{NMR}$ of $\left(101 \mathrm{MHz}, \mathrm{CDCl}_{3}\right): 198.2,137.1,133.1,128.6,128.3$ and $26.6 \mathrm{ppm}$.

Author Contributions: M.V. prepared the catalyst, reactions set up, production purification, analyses, data interpretation and prepared the manuscript; R.S. performed the reaction and data interpretation; A.L. and W.K. helped for SEM, TGA and BET analyses, W.R.T. edited the whole manuscript and supervised this work. All authors have read and agreed to the published version of the manuscript.

Funding: Georg Forster research fellowship (Alexander von Humboldt Foundation) for M.V.

Institutional Review Board Statement: Not applicable.

Informed Consent Statement: Not applicable.

Data Availability Statement: Data is contained within the article.

Acknowledgments: The authors wish to thank the Alexander von Humboldt Foundation for a Georg Forster research fellowship to M. Vafaeezadeh and the research unit NanoKat at the TU Kaiserslautern for financial support.

Conflicts of Interest: The authors declare no conflict of interest.

Sample Availability: Samples of the compounds are available from the authors.

\section{References}

1. Smidt, J.; Hafner, W.; Jira, R.; Sieber, R.; Sedlmeier, J.; Sabel, A. The Oxidation of Olefins with Palladium Chloride Catalysts. Angew. Chem. Int. Ed. 1962, 1, 80-88. [CrossRef]

2. Tsuji, J. Synthetic Applications of the Palladium-Catalyzed Oxidation of Olefins to Ketones. Synthesis 1984, 369-384. [CrossRef]

3. Zhang, Z.; Kumamoto, Y.; Hashiguchi, T.; Mamba, T.; Murayama, H.; Yamamoto, E.; Ishida, T.; Honma, T.; Tokunaga, M. Wacker Oxidation of Terminal Alkenes Over $\mathrm{ZrO}_{2}$-Supported Pd Nanoparticles Under Acid- and Cocatalyst-Free Conditions. ChemSusChem 2017, 10, 3482-3489. [CrossRef] [PubMed]

4. Donck, S.; Gravel, E.; Shah, N.; Jawale, D.V.; Doris, E.; Namboothiri, I.N.N. Tsuji-Wacker Oxidation of Terminal Olefins using a Palladium-Carbon Nanotube Nanohybrid. ChemCatChem 2015, 7, 2318-2322. [CrossRef]

5. Speziali, M.G.; Costa, V.V.; Robles-Dutenhefner, P.A.; Gusevskaya, E.V. Aerobic Palladium(II)/Copper(II)-Catalyzed Oxidation of Olefins under Chloride-Free Nonacidic Conditions. Organometallics 2009, 28, 3186-3192. [CrossRef]

6. Wang, J.; Cai, F.; Wang, E.; He, L. Supercritical carbon dioxide and poly(ethylene glycol): An environmentally benign biphasic solvent system for aerobic oxidation of styrene. Green Chem. 2007, 9, 882-887. [CrossRef]

7. Roussel, M.; Mimoun, H. Palladium-catalyzed oxidation of terminal olefins to methyl ketones by hydrogen peroxide. J. Org. Chem. 1980, 45, 5387-5390. [CrossRef]

8. Xie, M.; Yang, X.; Wu, C. A metalloporphyrin functionalized metal-organic framework for selective oxidization of styrene. Chem. Commun. 2011, 47, 5521-5523. [CrossRef]

9. Gao, X.; Zhou, J.; Peng, X. Efficient Palladium(0) supported on reduced graphene oxide for selective oxidation of olefins using graphene oxide as a 'solid weak acid'. Catal. Commun. 2019, 122, 73-78. [CrossRef] 
10. Keshipour, S.; Nadervand, $\mathrm{S} . \mathrm{Fe}_{3} \mathrm{O}_{4}$ nanoparticles as a new efficient co-catalyst for Pd(II) in Wacker oxidation of styrene using $\mathrm{H}_{2} \mathrm{O}_{2}$ as an oxidant. RSC Adv. 2015, 5, 47617-47620. [CrossRef]

11. Liu, W.; Huang, J.; Yang, Q.; Wang, S.; Sun, X.; Zhang, W.; Liu, J.; Huo, F. Multi-shelled Hollow Metal-Organic Frameworks. Angew. Chem. Int. Ed. 2017, 56, 5512-5516. [CrossRef] [PubMed]

12. Zhang, Y.; Li, Y.; Liu, L.; Han, Z. Palladium nanoparticles supported on UiO-66- $\mathrm{NH}_{2}$ as heterogeneous catalyst for epoxidation of styrene. Inorg. Chem. Commun. 2019, 100, 51-55. [CrossRef]

13. Cavani, F.; Teles, J.H. Sustainability in Catalytic Oxidation: An Alternative Approach or a Structural Evolution? ChemSusChem 2009, 2, 508-534. [CrossRef] [PubMed]

14. Mitsudome, T.; Umetani, T.; Nosaka, N.; Mori, K.; Mizugaki, T.; Ebitani, K.; Kaneda, K. Convenient and Efficient Pd-Catalyzed Regioselective Oxyfunctionalization of Terminal Olefins by Using Molecular Oxygen as Sole Reoxidant. Angew. Chem. Int. Ed. 2006, 45, 481-485. [CrossRef] [PubMed]

15. Wang, X.; Venkataramanan, N.S.; Kawanami, H.; Ikushima, Y. Selective oxidation of styrene to acetophenone over supported $\mathrm{Au}-\mathrm{Pd}$ catalyst with hydrogen peroxide in supercritical carbon dioxide. Green Chem. 2007, 9, 1352-1355. [CrossRef]

16. Xia, X.; Gao, X.; Xu, J.; Hu, C.; Peng, X. Selective Oxidation of Styrene Derivatives to Ketones over Palladium(0)/Carbon with Hydrogen Peroxide as the Sole Oxidant. Synlett 2017, 28, 607-610.

17. Byun, S.; Chung, J.; Jang, Y.; Kwon, J.; Hyeon, T.; Kim, B.M. Highly selective Wacker oxidation of terminal olefins using magnetically recyclable $\mathrm{Pd}-\mathrm{Fe}_{3} \mathrm{O}_{4}$ heterodimer nanocrystals. $\mathrm{RSC}$ Adv. 2013, 3, 16296-16299. [CrossRef]

18. Cao, Q.; Bailie, D.S.; Fu, R.; Muldoon, M.J. Cationic palladium(II) complexes as catalysts for the oxidation of terminal olefins to methyl ketones using hydrogen peroxide. Green Chem. 2015, 17, 2750-2757. [CrossRef]

19. Li, X.; Geng, W.; Zhou, J.; Luo, W.; Wang, F.; Wang, L.; Tsang, S.C. Synthesis of multicarboxylic acid appended imidazolium ionic liquids and their application in palladium-catalyzed selective oxidation of styrene. New J. Chem. 2007, 31, 2088-2094. [CrossRef]

20. Walker, K.L.; Dornan, L.M.; Zare, R.N.; Waymouth, R.M.; Muldoon, M.J. Mechanism of Catalytic Oxidation of Styrenes with Hydrogen Peroxide in the Presence of Cationic Palladium(II) Complexes. J. Am. Chem. Soc. 2017, 139, 12495-12503. [CrossRef]

21. Feng, B.; Hou, Z.; Wang, X.; Hu, Y.; Li, H.; Qiao, Y. Selective aerobic oxidation of styrene to benzaldehyde catalyzed by water-soluble palladium(II) complex in water. Green Chem. 2009, 11, 1446-1452. [CrossRef]

22. Lindner, E.; Schneller, T.; Auer, F.; Mayer, H.A. Chemistry in Interphases-A New Approach to Organometallic Syntheses and Catalysis. Angew. Chem. Int. Ed. 1999, 38, 2154-2174. [CrossRef]

23. Wu, Z.; Li, L.; Liao, T.; Chen, X.; Jiang, W.; Luo, W.; Yang, J.; Sun, Z. Janus nanoarchitectures: From structural design to catalytic applications. Nano Today 2018, 22, 62-82. [CrossRef]

24. Vafaeezadeh, M.; Thiel, W.R. Janus interphase catalysts for interfacial organic reactions. J. Mol. Liquid 2020, 315, 113735. [CrossRef]

25. Ji, X.; Zhang, Q.; Qu, X.; Wang, Q.; Song, X.; Liang, F.; Yang, Z. Poly(ionic liquid) Janus nanosheets towards dye degradation. RSC Adv. 2015, 5, 21877-21880. [CrossRef]

26. Kong, X.; Wu, C.; Feng, L.; Qu, J.; Liu, P.; Wang, X.; Zhang, X. Silica-based hierarchical porous Janus microcapsules: Construction and support of Au nano-particle catalyst inside. Chem. Commun. 2017, 53, 8054-8057. [CrossRef] [PubMed]

27. Zhang, M.; Tang, Z.; Fu, W.; Wang, W.; Tan, R.; Yin, D. An ionic liquid-functionalized amphiphilic Janus material as a Pickering interfacial catalyst for asymmetric sulfoxidation in water. Chem. Commun. 2019, 55, 592-595. [CrossRef]

28. Yuan, K.; Li, Y.; Huang, X.; Liang, Y.; Liu, Q.; Jiang, G. Templated synthesis of a bifunctional Janus graphene for enhanced enrichment of both organic and inorganic targets. Chem. Commun. 2019, 55, 4957-4960. [CrossRef] [PubMed]

29. Vafaeezadeh, M.; Breuninger, P.; Lösch, P.; Wilhelm, C.; Ernst, S.; Antonyuk, S.; Thiel, W.R. Janus Interphase Organic-Inorganic Hybrid Materials: Novel Water-Friendly Heterogeneous Catalysts. ChemCatChem 2019, 11, 2304-2312. [CrossRef]

30. Vafaeezadeh, M.; Wilhelm, C.; Breuninger, P.; Ernst, S.; Antonyuk, S.; Thiel, W.R. A Janus-type Heterogeneous Surfactant for Adipic Acid Synthesis. ChemCatChem 2020, 12, 2695-2701. [CrossRef]

31. Vafaeezadeh, M.; Schaumlöffel, J.; Lösch, A.; De Cuyper, A.; Thiel, W.R. Dinuclear Copper Complex Immobilized on a Janus-Type Material as an Interfacial Heterogeneous Catalyst for Green Synthesis. ACS Appl. Mater. Interfaces 2021, 13, 33091-33101. [CrossRef]

32. Karimi, B.; Khorasani, M. Selectivity Adjustment of SBA-15 Based Tungstate Catalyst in Oxidation of Sulfides by Incorporating a Hydrophobic Organic Group inside the Mesochannels. ACS Catal. 2013, 3, 1657-1664. [CrossRef]

33. Tsuji, J.; Nagashima, H.; Hori, K. A new preparative method for 1,3-dicarbonyl compounds by the regioselective oxidation of $\alpha, \beta$-unsaturated carbonyl compounds, catalyzed by $\mathrm{PdCl}_{2}$ using hydroperoxides as the reoxidant of $\mathrm{Pd}^{0}$. Chem. Lett. 1980, 9 , 257-260. [CrossRef] 